\title{
Reformando a lei de direitos autorais: desafios para o novo governo na área da cultura
}

\author{
Reforming the copyright law: culture related challenges for the new \\ government \\ Reformando la ley del derecho de autor: desafíos del nuevo gobierno en \\ la cultura
}

Jhessica Reia |jhessica.reia@fgv.br

Fundação Getúlio Vargas (FGV), Centro de Tecnologia e Sociedade (CTS-FGV). Rio de Janeiro, RJ, Brasil.

Pedro Nicoletti Mizukami | pedro.mizukami@fgv.br

Fundação Getúlio Vargas (FGV), Centro de Tecnologia e Sociedade (CTS-FGV). Rio de Janeiro, RJ, Brasil.

\section{Resumo}

O processo de reforma da lei de direitos autorais brasileira (Lei 9.610/98) teve início em 2007, durante a gestão de Gilberto Gil no Ministério da Cultura, a partir do Fórum Nacional de Direito Autoral, do debate público e da consulta online do anteprojeto de modernização da lei. Desde então, o país presenciou movimentos de avanço e estagnação da reforma, esperando-se que com a nomeação de Juca Ferreira para o Ministério da Cultura em 2015, a reforma da lei entre novamente em pauta. Contudo, existem diversos desafios nesse percurso que serão brevemente analisados neste artigo.

Palavras-chave: Lei de direitos autorais; Brasil; Ministério da Cultura; Pirataria; Consulta pública

\section{Abstract}

The process to reform the Brazilian Copyright Law (9.610/98) began in 2007, when Gilberto Gil was ahead of the Ministry of Culture, starting with the National Copyright Forum and public debates and online consultation for the law's modernization. Since then, the country has seen both movements to advance the 
reform and its stagnation, now expecting that, with the appointment of Juca Ferreira for the Ministry of Culture in 2015, the reform will return to the political agenda. However, there are many challenges ahead, which will be briefly analyzed in this article

Keywords: Copyright Law; Brazil; Ministry of Culture; Piracy; Public consultation.

\section{Resumen}

La reforma de la ley del derecho de autor brasileña (Lei 9.610/98) empezó en 2007, durante la gestión de Gilberto Gil en el Ministerio de Cultura, con el Foro Nacional de Derecho de Autor, el debate público y la consulta online del anteproyecto de modernización de la ley. Desde entonces, el país ha visto el desarrollo así como el estancamiento de la reforma. Se espera que, con el nombramiento de Juca Ferreira para el Ministerio de Cultura en 2015, la reforma de la ley entre de nuevo en la agenda política. Sin embargo, hay muchos desafíos en esta trayectoria, que serán analizados brevemente en este artículo.

Palabras clave: Derecho de autor; Brasil; Ministerio de Cultura; Piratería; Consulta pública. 


\section{Introdução}

A recente nomeação de Juca Ferreira para o Ministério da Cultura (MinC) trouxe consigo, entre outras discussões, uma perspectiva de retomada do processo de reforma da lei de direitos autorais (LDA) no Brasil, iniciado em 2007 com o Fórum Nacional de Direito Autoral. A lei vigente (9.610) completa dezessete anos em 2015 e continua notória por sua rigidez e inadequação a um mundo cada vez mais conectado, sendo considerada uma das piores do mundo, segundo a Consumers International's IP Watchlist - um ranking baseado na análise das liberdades de uso e acesso (para fins educacionais, por exemplo) que são permitidas pela legislação de direito autoral em diversos países. Em 2012, o Brasil figurava entre os cinco países com as piores leis de direito autoral dos trinta analisados ${ }^{1}$, ressaltando-se as parcas exceções e limitações contidas no texto.

Os embates entre direito autoral e tecnologia são antigos e foram se acentuando com o surgimento e difusão de mecanismos de reprodução e cópia de obras - vinil e fitas cassete, Napster e MP3, videocassete, redes peer-to-peer, plataformas como o YouTube, etc. - cada vez mais baratos e acessíveis ${ }^{2-3}$. As crescentes taxas de penetração da internet no mundo trouxeram à tona as lacunas existentes entre muitas legislações de proteção ao direito autoral e práticas de acesso e uso de obras pelo público, dando espaço para a ampliação tanto do discurso de guerra à pirataria quanto das práticas de enforcement.

O Brasil liga-se a um sistema internacional de proteção do direito autoral (como a Convenção de Berna de 1886 e o Acordo TRIPS, de 1994) e sofre a influência de posturas hegemônicas de combate à pirataria e de proteção dos interesses de atores das indústrias criativas. Em 2013, apenas 43\% dos domicílios brasileiros possuíam acesso à interneti; apesar das taxas de penetração da internet móvel aumentarem a cada ano, a inclusão digital através deste tipo de acesso não necessariamente leva à universalização do serviço e precisa ser debatida ${ }^{\text {ii }}$. Não obstante, houve profundas mudanças nas práticas de acesso dos usuários brasileiros a obras protegidas por direito autoral nos últimos anos, pressionando o Brasil a internalizar a agenda de combate à pirataria. Vale destacar, aqui, a criação do Conselho Nacional de Combate à Pirataria e Delitos contra a Propriedade Intelectual (CNCP) em 2004, fruto de um processo de pressão internacional4 .

A velocidade das mudanças no âmbito tecnológico acaba, muitas vezes, atropelando determinadas leis e a visão que se tem sobre práticas recorrentes. O tempo que o governo e a sociedade civil dispõem para discutir, construir e consolidar determinadas leis e políticas públicas raramente consegue acompanhar o ritmo do mercado, das inovações tecnológicas, dos novos modelos de negócios e das consequências de um cenário dinâmico na vida econômica e sociocultural do país. A academia, por sua vez, tem outro tempo e outros modos de participação nesses processos. Por isso, a reforma de uma lei como a de direitos autorais se mostra tão complexa e, ao mesmo tempo, necessária.

Tendo esse contexto em mente, pretende-se descrever brevemente o histórico do processo de reforma da LDA, para em seguida avaliar os desafios e perspectivas para a nova gestão do Ministério da Cultura em relação à reforma e, consequentemente, ao campo cultural no Brasil.

\footnotetext{
i Fonte: TIC domicílios e empresas 2013. Disponível em: http://www.cetic.br/tics/usuarios/2013/total-brasil/A4/, acessado em 21 de fevereiro de 2015. Apesar da taxa de domicílios com acesso à internet ser de $43 \%$, ao se fazer um recorte de renda ou distribuição geográfica, esses números variam muito. Por exemplo, $91 \%$ dos domicílios com renda familiar acima de dez salários mínimos têm acesso à internet, mas apenas $11 \%$ dos domicílios com renda familiar de até um salário afirmam ter acesso ao serviço em suas casas. No Norte, apenas $26 \%$; já no Sudeste e no Sul, as taxas são de $51 \%$.

ii Há dados crescentes de ativação de celulares com acesso à internet, conforme a Anatel, mas também existe o problema de que esses números não necessariamente correspondem ao número de pessoas que contratam pacotes de dados. Ver: http://www. cartacapital.com.br/blogs/intervozes/a-nao-ampliacao-do-acesso-movel-no-brasil-1782.html, acessado em 23 de fevereiro de 2015.
} 


\section{Breve histórico da reforma da LDA}

Diante do desafio de reformar a LDA brasileira, o Ministério da Cultura (na época sob administração de Gilberto Gil) criou o Fórum Nacional de Direito Autoral que, entre 2007 e 2009, realizou diversos encontros e debates entre sociedade civil, artistas, pesquisadores e representantes das indústrias criativas do país. O objetivo desse ciclo de debates e encontros setoriais foi o de "subsidiar a formulação da política autoral do Ministério da Cultura, bem como a possível revisão da legislação existente sobre a matéria e a redefinição do papel do Estado nessa seara", conforme comunicado divulgado pelo Ministério5.

Com base nessas e em outras reuniões, o Ministério da Justiça preparou um anteprojeto de reforma da lei, posteriormente submetido a uma consulta pública. Assim como no debate colaborativo do Marco Civil da Internet, o processo foi conduzido por meio de uma plataforma online, na qual o texto do anteprojeto podia ser comentado artigo por artigo. A plataforma ficou aberta entre 14 de junho e 31 de agosto de 2010, e recebeu 7.863 contribuições. Também foram recebidos documentos institucionais e particulares com posicionamentos sobre o texto proposto, os quais foram, igualmente, disponibilizados ao exame do público ${ }^{\mathrm{iii}}$.

Todo esse processo deu origem a um anteprojeto de lei mais flexível e consideravelmente mais adequado do que a lei vigente, contemplando a busca de maior equilíbrio com o interesse público, apresentando uma lista expandida de limitações de direito autoral, e entrando em temas como fiscalização da atividade da gestão coletiva (posteriormente alvo de lei própria). Já no parágrafo único do art. $1^{\circ}$, o anteprojeto apresentava um sinal claro de que, ao contrário da postura isolacionista promovida pela literatura jurídica autoralista então dominante, procurava atingir maior equilíbrio com o restante do ordenamento jurídico: "A proteção dos direitos autorais deve ser aplicada em harmonia com os princípios e normas relativos à livre iniciativa, à defesa da concorrência e à defesa do consumidor".

O artigo em questão pode até soar óbvio, mas a cultura em torno dos direitos autorais era, até então, fortemente insular. Não à toa, foi um dos mais controvertidos na consulta. Direitos autorais geralmente não são objeto de estudo em disciplina autônoma nas faculdades de direito do Brasil e, quando muito, o único contato dos alunos com o tema se dá via direito civil, no estudo do contrato de edição, ou via direito penal, a partir do crime de violação de direito autoral (art. 184 do Código Penal). Os manuais de direito autoral - muitas vezes escritos por advogados que representam detentores de direitos - usualmente tratam o tema como autossuficiente, e com um viés nitidamente voltado para uma visão maximalista dos interesses de intermediários na cadeia de produção cultural. Ao dizer de maneira tão direta que o direito de autor interage com e sofre influência de outras normas e subsistemas, tal como o direito antitruste e do consumidor, o anteprojeto provocou um bem-vindo mal-estar em certos participantes do processo de consulta. Outros tópicos, como o das exceções e limitações, foram igualmente polêmicos.

Em 2008, quando Gilberto Gil resolveu deixar o cargo, o presidente Lula nomeou Juca Ferreira para substituí-lo, garantindo a continuidade do processo. Com a eleição de Dilma Rousseff em 2010, contudo, foi indicada Ana de Hollanda para a pasta da cultura. A proximidade da nova ministra com a indústria fonográfica e com o Escritório Central de Arrecadação e Distribuição (Ecad) foi recebida com apreensão por diversos participantes do processo. Uma das primeiras medidas de Ana de Hollanda no cargo, com efeito, foi a remoção das licenças Creative Commons do site do MinC, o que foi interpretado como um forte sinal de que a orientação do novo Ministério iria em sentido diametralmente oposto ao dos anos Gil e Juca. Houve também a substituição dos funcionários da Diretoria de Direitos Intelectuais, caso de Marcos Souza, o principal responsável pela condução do processo. Destaca-se, ainda, uma revisão do texto do anteprojeto, vazado pela Revista Fórum 6 , que apesar de tornar o texto mais brando, não era uma revisão substancial.

iii Ver: http://www2.cultura.gov.br/consultadireitoautoral/, acessado em 23 de fevereiro de 2015. 
O Ministério, nesse período, não demonstrou sinais de que tinha de fato comprado a ideia de uma reforma da LDA, e tampouco de que estava empenhado em fazer com que ela se tornasse realidade.

A ministra ficou menos de dois anos no cargo e, em 2012, Marta Suplicy a sucedeu, indicando que daria continuidade à gestão de Gilberto Gil e Juca Ferreira, e que prosseguiria no processo de modernização da LDA. A partir desse momento, o anteprojeto passou por novas modificações e foi enviado à Casa Civil, em versão que ainda não foi divulgada ao público. Apesar de não ter progredido durante a passagem de Marta Suplicy pelo cargo, o tema da gestão coletiva para música acabou sendo destacado do pacote inicial da reforma e transformado na Lei 12.853 em 2013.

Com a aprovação do Marco Civil da Internet (Lei 12.965) em abril de 2014, mais uma barreira foi derrubada. Como o Marco Civil ocupava a primeira posição na lista de prioridades legislativas do governo federal em seus meses finais de tramitação, acabou por desincentivar o envio da proposta de modernização da LDA ao Congresso em 2013. Uma vez aprovado, a acirrada disputa das eleições no segundo semestre de 2014 também atrasou o envio do anteprojeto ${ }^{7}$. Cabe aqui, entretanto, uma pequena digressão: o Marco Civil acabou excluindo explicitamente os direitos autorais do regime de responsabilidade de intermediários previsto no art. 18 e seguintes da lei. A pressão das entidades representantes de detentores de direitos autorais foi canalizada via Organizações Globo, conforme reportado em matéria do Último Segundo ${ }^{8}$. Com o processo de debate público para a regulamentação do Marco Civil aberto em fevereiro de 2015, fica o questionamento, já para o início do novo governo, de qual será a solução adotada.

\section{Desafios e perspectivas para o novo governo}

Nesse cenário conturbado e de descontinuidades existem diversos desafios a serem enfrentados por Juca Ferreira, que reassumiu o Ministério da Cultura no início de 2015 - trazendo consigo nomes da sociedade civil e da academia para compor a pasta, muitos deles participantes ativos nos debates referentes à reforma da LDA.

Mesmo passada a turbulência das eleições, com a presidente Dilma reeleita para seu segundo mandato, ainda há dúvida sobre quando, exatamente, ocorrerá o envio do anteprojeto ao Congresso. Existem decisões de conveniência política sobre o momento oportuno de se apresentar um projeto de lei do governo sobre um tema controvertido, em um contexto de fragilidade e instabilidade política. Outros temas, ainda, podem ser vistos como ao mesmo tempo mais prioritários e menos controvertidos, como a lei sobre proteção a dados pessoais, por exemplo, em processo de debate público simultâneo ao da regulamentação do Marco Civil.

Além disso, é essencial discutir a possível erosão - na prática, não por princípio - das exceções e limitações em um cenário cada vez mais marcado pelo fortalecimento, no mercado, de plataformas de distribuição de conteúdo, principalmente via streaming, e de tecnologias de automação de gestão de direitos que acabam implementando, mesmo em países nos quais eles não são vigentes, regimes como o da Digital Millennium Copyright Act (DMCA) estadunidense. Em alguns casos, chega-se a regimes DMCA plus, que vão além do modelo de notice-and-takedown e estabelecem modalidades adicionais de remoção, bloqueio, e monetização de conteúdo. Isso pode ocorrer a partir da implementação de tecnologias de fingerprinting como a do Content ID do YouTube ${ }^{\text {iv }}$, associadas a regimes que vinculam a manutenção de contas de usuários a seu "bom comportamento" e respeito aos direitos autorais, ou até mesmo a partir de acordos entre plataformas e detentores de direitos. O Universal Music Group (UMG), por exemplo, tem um acordo com o SoundCloud e não precisa valer-se de um sistema de notificações ou até mesmo acionar a plataforma quando quer remover conteúdo: tem acesso direto ao sistema ${ }^{9}$.

O mercado, arranjos econômicos, modelos de negócios e as inovações tecnológicas são bastante dinâmicos, e a velocidade dos processos políticos e legislativos geralmente não consegue manter o mesmo

iv Ver: https://support.google.com/youtube/answer/2797370?hl=en, acessado em 24 de fevereiro de 2015. 
ritmo. Isso é algo a se levar em conta quando tivermos a oportunidade de analisar o texto atual do anteprojeto de reforma da LDA.

O contexto internacional, entretanto, pode servir como incentivo para que a discussão seja retomada. O Tratado de Marrakesh (2013), do qual o Brasil é um dos signatários - e para a criação do qual foi um dos atores fundamentais, via Itamaraty e o próprio $\mathrm{MinC}$ - representou um ponto de virada nas discussões sobre novos tratados de exceções e limitações no âmbito da Organização Mundial da Propriedade Intelectual (Ompi), causando uma mudança de paradigma, no âmbito multilateral, quanto ao escopo possível de instrumentos internacionais de direitos autorais. Pela primeira vez, transferiu-se o foco de um desses instrumentos ao usuário e não tão-somente ao detentor de direitos ou autor. O processo iniciado pelo Tratado de Marrakesh continua, com discussões sobre potenciais tratados de exceções e limitações tanto para bibliotecas e arquivos quanto para educação. Há, aqui, também, uma série de dificuldades: uma agenda potencialmente travada pelo Tratado de Radiodifusão e a articulação menos organizada por parte dos setores contemplados: os deficientes visuais são mais organizados e homogêneos em seus interesses.

De qualquer forma, a nomeação de Juca Ferreira trouxe esperanças de que o anteprojeto possa enfim seguir adiante, a fim de retomar as discussões sobre a modernização da lei de direitos autorais, complementando as atuais discussões em torno do Marco Civil e do anteprojeto de lei de proteção de dados pessoais.

\section{Referências}

1. IP Watchlist [Internet]. London: Consumers International; 2012 [citado em 21 fev. 2015]. Disponível em: http://a2knetwork.org/consumers-international-ip-watchlist-report-2012.

2. Coleman, M. Playback: from the Victrola to MP3, 100 years of music, machines and money. Cambridge: Da Capo Press; 2005.

3. Lessig, L. Free culture: how big media uses technology and the law to lock down culture and control creativity. New York: Penguin Books; 2004.

4. Karaganis, J. (Org.). Media piracy in emerging economies. New York: SSRC books; 2011.

5. Fórum Nacional do Direito Autoral 2007/2008 [Internet]. Brasília: Ministério da Cultura; 2007/2008 [citado 24 fev. 2015]. Disponível em: http://www.cultura.gov.br/documents/18021/130362/forumnacional-do-direito-autoral-2007-2008.pdf/d7830598-d295-43dd-ac58-d49a1f32d29f.

6. Grupo de Pesquisa de Inovação em Saúde da Escola Nacional de Saúde Pública - GIS/ENSP/Fiocruz, Proposta de LDA do MinC ainda favorece Ecad [Internet]. Brasil: Revista Fórum; 2011 [citado em 24 fev. 2015]. Disponível em: http://www.revistaforum.com.br/blogdorovai/2011/12/06/ortellado-e-allanrocha-proposta-de-Ida-do-minc-ainda-favorece-ecad/.

7. Copyright Week: $\mathrm{O}$ que aconteceu com a reforma do direito autoral no Brasil? [Internet]. Rio de Janeiro: Creative Commons; 2014 [citado em 23 fev. 2015]. Disponível em: http://www.creativecommons.org.br/ blog/copyright-week-pt

8. Marco Civil da Internet muda para atender demanda da Rede Globo [Internet]. Brasil: Último Segundo; 2013 [citado em 24 fev. 2015]. Disponível em: http://ultimosegundo.ig.com.br/politica/2013-11-06/ marco-civil-da-internet-muda-para-atender-demanda-da-rede-globo.html

9. SoundCloud Has Given Universal Music Group The Ability To Directly Remove Content [Internet]. Estados Unidos: Techdirt; 2014 [citado em 24 fev. 2015]. Disponível em: https://www.techdirt.com/ articles/20140702/10252827760/soundcloud-has-given-universal-music-group-ability-to-directly-removecontent.shtml 